\title{
Multi-locus analysis of human infective Cryptosporidium species and subtypes using ten novel genetic loci
}

\author{
Maha Bouzid ${ }^{1}$, Kevin M Tyler ${ }^{1}$, Richard Christen², Rachel M Chalmers ${ }^{3}$, Kristin Elwin ${ }^{3}$, Paul R Hunter ${ }^{{ }^{*}}$
}

\begin{abstract}
Background: Cryptosporidium is a protozoan parasite that causes diarrheal illness in a wide range of hosts including humans. Two species, C. parvum and C. hominis are of primary public health relevance. Genome sequences of these two species are available and show only 3-5\% sequence divergence. We investigated this sequence variability, which could correspond either to sequence gaps in the published genome sequences or to the presence of species-specific genes. Comparative genomic tools were used to identify putative species-specific genes and a subset of these genes was tested by PCR in a collection of Cryptosporidium clinical isolates and reference strains.

Results: The majority of the putative species-specific genes examined were in fact common to C. parvum and C. hominis. PCR product sequence analysis revealed interesting SNPs, the majority of which were species-specific. These genetic loci allowed us to construct a robust and multi-locus analysis. The Neighbour-Joining phylogenetic tree constructed clearly discriminated the previously described lineages of Cryptosporidium species and subtypes.

Conclusions: Most of the genes identified as being species specific during bioinformatics in Cryptosporidium sp. are in fact present in multiple species and only appear species specific because of gaps in published genome sequences. Nevertheless SNPs may offer a promising approach to studying the taxonomy of closely related species of Cryptosporidia.
\end{abstract}

\section{Background}

At least eight Cryptosporidium species infect humans [1]; however, only two species are of major significance to public health by causing the majority of human cases both sporadic and outbreak related cases, C. hominis and C. parvum [2-5]. Cryptosporidium parvum is zoonotic and infects a wide range of animal hosts including humans, whereas C. hominis is generally restricted to humans [6]. Therefore, the main phenotypic difference between C. hominis and C. parvum is the host range [1-3]. In addition, these two Cryptosporidium species differ in geographical and temporal distribution and pathogenicity $[7,8]$. Differential risk factors and transmission routes have also been identified $[3,7,9]$. However human infections are not solely linked to these two

\footnotetext{
* Correspondence: Paul.Hunter@uea.ac.uk

'Biomedical Research Centre, School of Medicine, Health Policy and Practice, University of East Anglia, Norwich NR4 7TJ, UK

Full list of author information is available at the end of the article
}

species and other species and genotypes have been associated with illness [10]. These additional species and genotypes are therefore considered emergent. This was the case of the rabbit genotype, the aetiological agent in an outbreak of waterborne human cryptosporidiosis in Northamptonshire, East Midlands, England [11,12]. Subsequent characterization studies revealed that the rabbit genotype, which caused this outbreak, corresponds to Cryptosporidium cuniculus (Inman and Takeuchi, 1979) [13].

The public health relevance of $C$. parvum and C. hominis has driven a bias in Cryptosporidium research towards these two species. Indeed, the genomes of C. parvum and C. hominis (IOWA and TU502 reference strains, respectively) have been sequenced $[14,15]$. The genome sequencing of $C$. muris, a less relevant Cryptosporidium species from a public health perspective, is underway [16]. The genomic data for all 3 genome representatives is available online http://CryptoDB. 
org. The genome sizes for $C$. parvum and $C$. hominis are 9.11 and $9.16 \mathrm{Mb}$, respectively. The GC content is $30 \%$ and the coding region is of about $6 \mathrm{Mb}$ [15]. The number of published genes is slightly higher in C. hominis than in C. parvum: 3,994 genes versus 3,952 genes. The significance of these 42 missing genes is not clear. The average gene length is comparable between the 2 species: $1.57 \mathrm{~kb}$ and $1.72 \mathrm{~kb}$, for C. hominis and C. parvum, respectively. Genome comparison showed that C. hominis and C. parvum are very similar. This high level of sequence similarity limited the ability of comparative genomics to improve annotation, identify conserved non-coding sequence elements and study gene and protein evolution [16]. More importantly, this high sequence similarity hindered better understanding of host specificity and virulence mechanisms as was anticipated from the genome projects [17]. In fact, C. hominis and $C$. parvum genomes exhibit only 3-5\% sequence divergence, with no large insertions, deletions or rearrangements [15]. The authors stated that the gene complements of the two species are essentially identical because the few C. parvum genes not found in C. hominis are proximal to known sequence gaps. However, uncertainty about the amount of sequence variation between $C$. parvum and C. hominis persists due to the incomplete status of the $C$. hominis genome. Nevertheless, it has been concluded that the phenotypic differences between $C$. hominis and C. parvum are caused by polymorphisms in coding regions and differences in gene regulation $[15,18]$. The role of this minimal genetic variability between C. hominis and C. parvum in the phenotypic differences is now much more accessible for investigation. In fact, these genes may include hitherto valuable epidemiological markers and previously unnoticed genetic determinants of host specificity and virulence. In addition, such markers would also serve as typing targets.

The aim of this study was to survey the published $C$. parvum and C. hominis genomes for incomplete regions and missing genes in order to identify novel genotyping markers. These genes are likely to contribute to the phenotypic differences between C. parvum and C. hominis and therefore might be potential genetic determinants of host tropism.

\section{Results}

Initial screening by Reciprocal Blast and retention of coding sequences showing a level of similarity below $10 \%$ (and supported by significant $\mathrm{p}$ values) identified 117 and 272 putative species-specific genes for C. hominis and C. parvum, respectively. The majority of C. parvum putative specific genes were annotated, while $C$. hominis putative specific genes corresponded mainly to hypothetical proteins. Subsequently, the secondary screen decreased the number of the predicted genes to 93 and 211 genes for C. hominis and C. parvum, respectively.

Initially, a subset of ten genes was selected semi-randomly with preference to annotated genes (Table 1). This subset of genes was tested experimentally by PCR in a collection of Cryptosporidium clinical isolates and reference strains (Table 2). Surprisingly, 90\% (9/10) of the genes tested were present in both $C$. hominis and C. parvum. PCR results for Cgd2_80 and Chro.50330 genes are shown in Figure 1. There was no discernable difference between PCR results of C. parvum and $C$. hominis clinical isolates and reference strains by agarose gel electrophoresis. DNA from isolate Cp4 did not amplify using Chro.30149 primers. Further testing of other putative species-specific genes confirmed the general trend. The majority of the predicted genes were therefore common to both Cryptosporidium species. Consequently, we considered whether the observed ubiquity of the predicted specific genes represented the closeness between C. hominis and C. parvum or whether these primers would also amplify orthologous genes from other Cryptosporidium species. C. meleagridis DNA was amplified by PCR for $8 / 10$ genes $(80 \%)$, only, Cgd2_2430 and Chro.20156 PCR reactions were negative (Table 3).

Interestingly, for $C g d 2 \_2430$ gene, only $C$. andersoni DNA was amplified by PCR. For Cgd6_5020, only C. felis DNA was PCR positive and for Chro.30149 primers, cervine genotype DNA was amplified. C. andersoni, cervine genotype and $C$. felis DNA was amplified by $10 \%(1 / 10)$ of primers tested. C. baileyi DNA was not amplified by any of the primers tested (Table 3 ).

All positive PCR products were sequenced. PCR product sequences are available online [GenBank: GU904212-GU904405]. The alignments of PCR product sequences for each gene are shown [additional file 1]. One PCR product of $C$. meleagridis DNA using Chro.50330 primers did not generate good sequence and was therefore excluded from the analysis. In addition, PCR products for C. andersoni, C. felis and cervine genotype did not generate good quality sequences and they were not included in the analysis.

Sequence analysis of these novel genetic loci showed interesting genetic polymorphisms and 78 Single nucleotide polymorphisms (SNP) were detected. These SNPs were detected from a total number of 4150 nucleotides, corresponding to an average of 1 SNP every $53 \mathrm{bp}$. The number of SNPs was variable for each gene, ranging from 1 SNP every $30 \mathrm{bp}$ for Cgd2_2430 to less than one SNP per 330 bp for Chro.30149. The SNP results for each gene are summarized in Table 4. Of the 78 SNPs, $61(78.3 \%)$ were species-specific, thus defining an interesting feature of this subset of genes identified by 
Table 1 List of Cryptosporidium genes selected for this study

\begin{tabular}{|c|c|c|c|c|c|}
\hline $\begin{array}{l}\text { Primer } \\
\text { name }\end{array}$ & Gene function (CryptoDB) & Sequence & $\operatorname{Tm}\left({ }^{\circ} \mathrm{C}\right)$ & $\begin{array}{c}\text { Annealing } \\
\text { temperature } \\
\left({ }^{\circ} \mathrm{C}\right)\end{array}$ & $\begin{array}{c}\text { Size of } \\
\text { amplified } \\
\text { fragment }\end{array}$ \\
\hline $\mathrm{cgd2} 280 \mathrm{~F}$ & $A B C$ transporter family protein & GGA TTG GGG GTG ATA TGT TG & 68 & 60 & $266 \mathrm{bp}$ \\
\hline $\mathrm{cgd2} \_80 \mathrm{R}$ & & ACC TCC AAG CTG TGT TCC AG & 70 & & \\
\hline cgd6_200 F & Oocyst wall protein 8 & CGT TCC AAC AAT GGT GTG TC & 68 & 60 & $447 \mathrm{bp}$ \\
\hline cgd6_200 R & & GCA GCT GGA GTG CAA TCA TA & 68 & & \\
\hline $\mathrm{cgd8}$ _2370 F & Adenosine kinase like ribokinase & CAG GAA TTG CTC ACG GAA AT & 66 & 60 & $685 \mathrm{bp}$ \\
\hline cgd8_2370 R & & CCT TAA ATG CAT CCC CAC AG & 68 & & \\
\hline Chro.50317 F & RNA polymerase $A /$ beta'$^{\prime} / A^{\prime \prime}$ subunit & GAT TTा GAT GGA GGG TCT CG & 68 & 60 & $752 \mathrm{bp}$ \\
\hline Chro.50317 R & & CTG GCA GCT TCA ACA CCA TA & 68 & & \\
\hline Chro.30149 F & Ubiquitin-protein ligase 1 & GGG ATT AGA TGC AGG TGG TG & 70 & 60 & $331 \mathrm{bp}$ \\
\hline Chro.30149 R & & TGG ATG CTC CAG CAT TAC AT & 66 & & \\
\hline Chro.50457 F & Erythrocyte membrane-associated antigen & CCT TTG GAT TGT CCC GAA TA & 66 & 60 & $394 \mathrm{bp}$ \\
\hline Chro.50457 R & & CAA TGC CAT ATG ATT TGA GAA AAA & 65 & & \\
\hline cgd6_5020 F & Protein with WD40 repeats & AAC AGG AGC TGA CGA TTG CT & 60.4 & 57 & $271 \mathrm{bp}$ \\
\hline cgd6_5020 R & & ACA TTG TGC CAT TCC AAG GT & 58.35 & & \\
\hline cgd2_2430 F & $\begin{array}{l}\text { Ximpact ortholog conserved protein } \\
\text { seen in bacteria and eukaryotes }\end{array}$ & GTA ACG CAT GGC GAA CCT AT & 60.4 & 57 & $389 \mathrm{bp}$ \\
\hline cgd2_2430 R & & AAG ATC AGC CTT GCA GCA TT & 58.35 & & \\
\hline Chro.20156 F & Hypothetical protein & TTC GCT TGA AGC CGT AAA CT & 58.35 & 57 & $247 \mathrm{bp}$ \\
\hline Chro.20156 R & & GGC ATT GAT ACC AGG CAA GT & 60.4 & & \\
\hline Chro. $50330 \mathrm{~F}$ & Leucyl tRNA synthetase & TCG GTA CAG CAT CAG GTT CA & 60.4 & 57 & $368 \mathrm{bp}$ \\
\hline Chro.50330 R & & GTT TाT GCT CCC CCA GTT Tा & 58.35 & & \\
\hline Cry-15 & Oocyst wall protein gene [16] & GTA GAT AAT GGA AGA GAT TGT G & 57.08 & 60 & $555 \mathrm{bp}$ \\
\hline Cry-9 & & GGA CTG AAA TAC AGG CAT TAT CTT G & 61.3 & & \\
\hline
\end{tabular}

Gene name and annotation is according to CryptoDB. For each gene, a set of primers was designed. Primer name is the gene name followed by $\mathrm{F}$ or $\mathrm{R}$ (for forward and reverse, respectively). For each gene, primer sequences, annealing temperature and PCR product size are detailed.

comparative genomics. The proportion of species-specific SNPs ranged from $66.7 \%$ for Cgd8_2370 and Chro.50317 genes to $100 \%$ for Chro.50330 and Chro.50457 (Table 4). In addition, 64.2\% (50/78) of the SNPs detected were synonymous, thus maintaining the protein sequence. The 28 non-synonymous SNPs were not evenly distributed between the loci. In fact, the proportion of non synonymous SNPs was low for the majority of the genes ranging from $0 \%$ to $25 \%$ for Chro.50330 and Cgd6_200, respectively (Table 4). On the contrary, for Chro.50317 and Chro.20156 genes, $66.7 \%$ and $83.4 \%$ of the SNPs were non-synonymous. The annotations of these genes are RNA polymerase and hypothetical proteins, respectively. The significance and effect of these mutations would need to be investigated experimentally. In addition to the 61 species-specific SNPs allowing discrimination between C. hominis and $C$. parvum, the sequence analysis showed 5 SNPs specific for C. cuniculus isolates and 3 SNPs specific for the anthroponotic $C$. parvum subtype. The newly identified SNPs were confirmed experimentally by PCR-RFLP, as sequence alignments were used to identify differential restriction endonuclease recognition sites between the main species tested (Data not shown).
SNP analysis was performed in a pair-wise manner between isolate groups and subtypes using the logical function "IF" of the Microsoft Excel software to discriminate between variables. When the SNPs were identical between the 2 groups, the value " 0 " was attributed, while if the 2 SNPs were different, the value " 1 " was assigned and the values summed for each group. The number of base pair differences between the groups is shown in Table 5. These scores represent the genetic variability between the main isolate groups. The newly identified SNPs showed clear genetic difference patterns between species and subtypes of Cryptosporidium. It is noticeable that the genetic differences of $C$. hominis and C. parvum to C. meleagridis were comparable (5.50 and $5.05 \%$, respectively). This analysis showed a minimal genetic variability between $C$. hominis and C. parvum (1.72\%) (Table 5). Interestingly, the genetic difference between $C$. parvum and C. parvum anthroponotic subtype was $0.13 \%$, while a slightly higher genetic difference was observed between $C$. hominis and C. cuniculus isolates $(0.27 \%)$.

Sequences of the ten genetic loci and of the COWP (Cryptosporidium oocyst wall protein) gene were used for Multi-locus Analysis (MLA). All the retrieved 
Table 2 Epidemiological and genotyping data of Cryptosporidium isolates tested

\begin{tabular}{|c|c|c|c|c|c|}
\hline Isolate & Original host & Origin & $\begin{array}{l}\text { COWP- } \\
\text { RFLP }\end{array}$ & $\begin{array}{l}18 \mathrm{~s} \text { sequencing } \\
\text { (genotyping) }\end{array}$ & $\begin{array}{l}\text { gp60 sequencing } \\
\text { (subtyping) }\end{array}$ \\
\hline C. parvum IOWA & $\begin{array}{l}\text { Bovine (passaged in } \\
\text { calves) }\end{array}$ & lowa, USA & C parvum & & \\
\hline C. hominis TU502 & $\begin{array}{l}\text { Human (passaged in } \\
\text { pigs) }\end{array}$ & Uganda & Chominis & & \\
\hline $\begin{array}{l}\text { C. parvum } \\
\text { Moredun }\end{array}$ & $\begin{array}{l}\text { Cervine (passaged in } \\
\text { calves) }\end{array}$ & Scotland & C parvum & & \\
\hline Ch2 & Human & Yorkshire, England & Chominis & C. hominis GQ983348 & IbA10G2 GQ983356 \\
\hline Ch3 & Human & North Wales & Chominis & C. hominis GQ983350 & IbA10G2 GQ983358 \\
\hline Ch4 & Human & Cumbria, England & Chominis & C. hominis GQ983352 & IbA10G2 GQ983360 \\
\hline Cp2 & Human & Devon, England & C parvum & C parvum GQ983349 & |laA18G3R1 GQ983357 \\
\hline Cp3 & Human & Cumbria, England & C parvum & C parvum GQ983351 & IlaA17G1R1 GQ983359 \\
\hline Cp4 & Human & Grampian, Scotland & C parvum & C. parvum GQ983353 & IlaA15G2R1 GQ983361 \\
\hline W7265 (W65) & Human & Leicestershire, England & C parvum & C. parvum GU971620 & IICA5G3 GU971624 \\
\hline W7266 (W66) & Human & Leicestershire, England & C parvum & C. parvum GU971621 & IICA5G3 GU971625 \\
\hline W7267 (W67) & Human & Leicestershire, England & C parvum & C. parvum GU971622 & $\begin{array}{l}\text { IlcA5G3 } \\
\text { GU971626 }\end{array}$ \\
\hline W7270 (W70) & Human & Leicestershire, England & C parvum & C. parvum GU971623 & $\begin{array}{l}\text { IlcA5G3 } \\
\text { GU971627 }\end{array}$ \\
\hline W17330 (rabbit 1) & Human & $\begin{array}{c}\text { Northampton-shire, } \\
\text { England }\end{array}$ & Chominis & Rabbit genotype FJ262726 & VaA18 FJ262732 \\
\hline W18455 (rabbit 2) & Human & Shropshire, England & Chominis & Rabbit genotype GU971628 & VaA23 GU971631 \\
\hline W17525 (rabbit 3) & Human & Suffolk, England & Chominis & Rabbit genotype GU971629 & VaA32 GU971632 \\
\hline (W17435 (rabbit 4) & Human & Essex, England & Chominis & Rabbit genotype GU971630 & VaA22 GU971633 \\
\hline
\end{tabular}

Details of the host, the geographical origin and the genotyping data of C. parvum and C. hominis isolates and reference strains, which DNA was tested during this study.

sequences allowed comparison of a total 4469 bp. A Neighbour-Joining Tree was generated based on these sequences using MEGA software. The tree showed clear discrimination between $C$. parvum and C. hominis isolates (Figure 2A). Within each group, there were two clusters corresponding to isolate subtypes: C. parvum and $C$. parvum anthroponotic subtype and $C$. hominis and $C$. cuniculus. All groups and clusters were supported by high bootstrap values. Unweighted Pair Group Method with Arithmetic Mean (UPGMA) phylogenetic method was also tested to construct phylogenetic trees and gave the same topology with similar bootstrap values (data not shown). There was no discrimination between the different isolates belonging to the main species groups, despite distinct gp60 subtypes. However, TU502 strain showed some sequence divergence and was grouped separately within the $C$. hominis cluster. This is due to the presence of a unique SNP at position 132 on Cgd8_2370 gene, which was confirmed by 3 independent rounds of sequencing. Cryptosporidium meleagridis sequences were included in the MLA and used as an out group. Cryptosporidium meleagridis DNA did amplify 8/10 loci tested, however, for 2 loci (Cgd8_2370 and Chro.50330 genes) the generated sequences were not of high quality and were not used for analysis. Therefore, the differences between this strain and the other isolates were based only on 2853 bp comparisons for 7 genetic loci. The phylogenetic tree with $C$. meleagridis as the out group also allowed discrimination of Cryptosporidium species and subtypes in a similar manner than the tree presented in Figure 2A. The two phylogenetic trees showed similar bootstrap values (Figure $2 \mathrm{~A}$ and $2 \mathrm{~B}$ ).

\section{Discussion}

In this study, comparative genomic tools were used to identify putative species-specific genes for $C$. hominis and $C$. parvum based on published genome sequences. The initial bioinformatics primary and secondary screening allowed the identification of 93 and 211 genes for $C$. hominis and C. parvum, respectively. This finding is somewhat lower than the number of orthologous gene clusters for C. parvum and C. hominis reported previously in a study of the Apicomplexa [19]. Initially, 10 of these genes were tested by PCR in a collection of Cryptosporidium clinical isolates and reference strains. PCR screening of the predicted putative species-specific genes showed that the majority of the genes were not as predicted. In fact, $90 \%$ of the genes tested were present in both C. hominis and C. parvum isolates. This would 


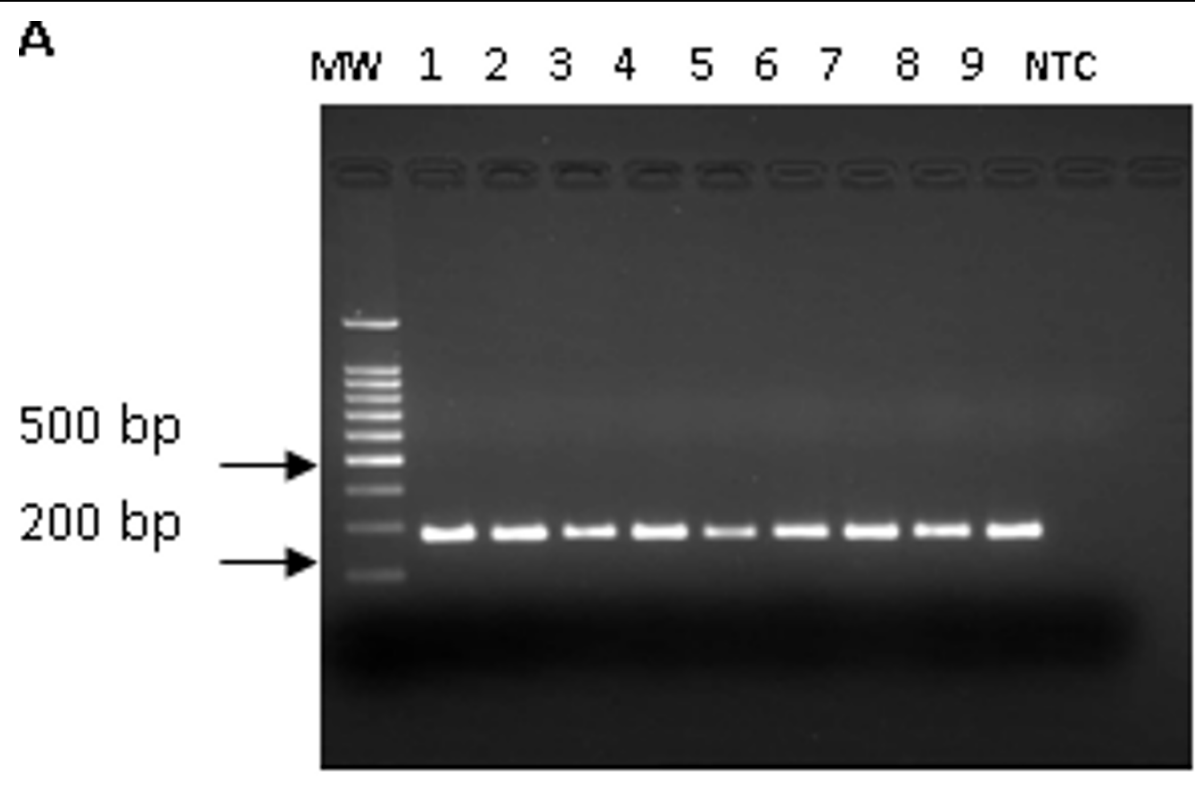

B

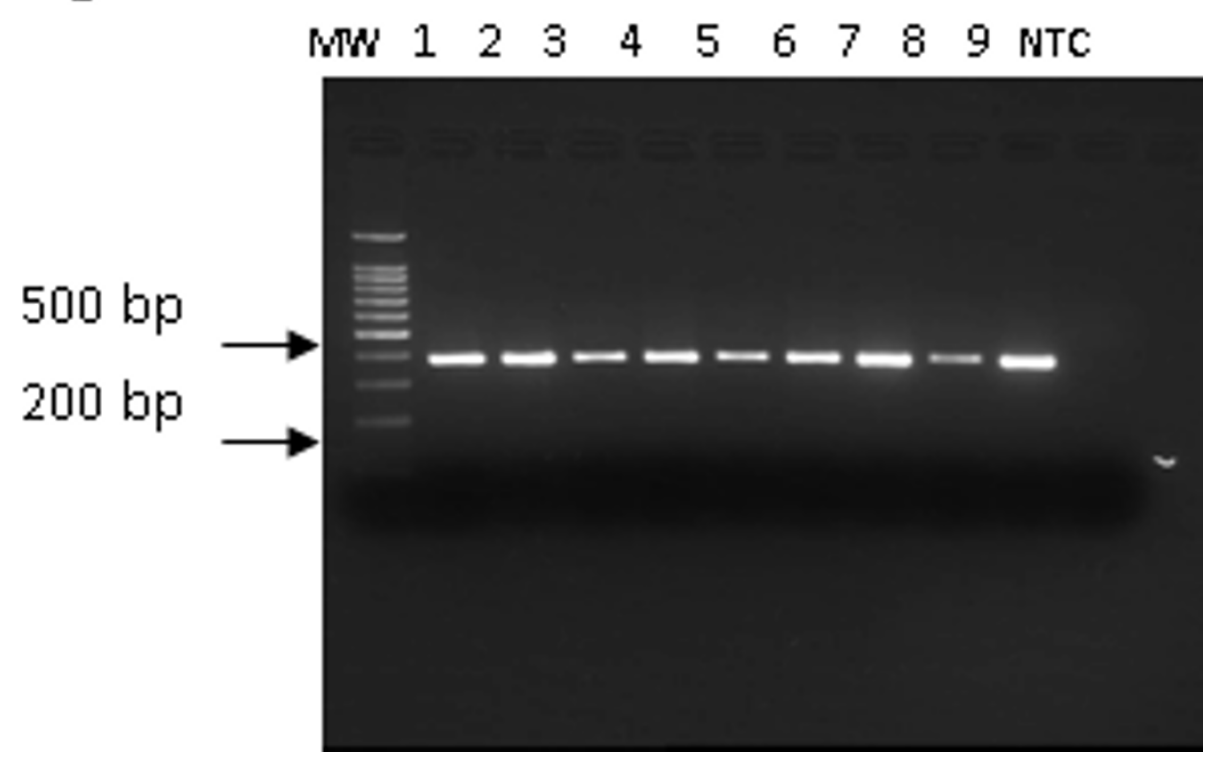

Figure 1 Amplification of Cryptosporidium DNA from clinical isolates and reference strains. A: amplification of 266 bp of Cgd2_80 gene, B: amplification of $368 \mathrm{bp}$ of Chro.50330 gene. Both Cryptosporidium species and all isolates were PCR positive. MW: molecular weight, 1: Cp2, 2: Cp3, 3: Cp4, 4: Ch2, 5:Ch3, 6: Ch4, 7: lowa, 8: Moredun, 9: TU502, NTC: non template control. 
Table 3 PCR results of other Cryptosporidium species

\begin{tabular}{cccccc}
\hline & C. andersoni & C. felis & Cervine genotype & C. meleagridis & C. baileyi \\
\hline Cgd2_80 & - & - & - & - & - \\
Cgd2_2430 & + & - & - & + & - \\
Cgd6_200 & - & - & - & + & - \\
Cgd6_5020 & - & + & - & + & - \\
Cgd8_2370 & - & - & - & + & - \\
Chro.20156 & - & - & - & + \\
Chro.50317 & - & - & - & + \\
Chro.50330 & - & - & + & + \\
Chro.30149 & - & - & - & + \\
Chro.50457 & - & - & + & + \\
\hline
\end{tabular}

DNA from C. andersoni, C. felis, cervine genotype, C. meleagridis and C. baileyi was tested by PCR using the newly designed primers.

suggest caution when using lineage-specific genes for taxonomic analysis at least until published genomes are known to be complete [19].

The discrepancy between bioinformatics and PCR is likely to be caused, at least in part, by the fact that the $C$. hominis TU502 genome is neither completed nor fully assembled, which is consistent with the smaller number of putative C. hominis specific genes as compared to those specific to $C$. parvum. However, this seems to be in disagreement with the finding that the C. hominis genome has 42 genes more than the $C$. parvum genome. Nevertheless, it is plausible that the status of the C. hominis genome had hindered the accuracy of the initial comparative genomic analysis because the selected genes may correspond to sequence gaps reported by the authors [15]. Further testing of an additional ten predicted putative specific genes for each species confirmed the general trend of similar amplification from both species. Therefore, the majority of the genes seem to be common to both species. However, an improved comparative genomic analysis has been made possible by the fast progress made towards the completion of $C$. muris genome. At the time of writing, $8.9 \mathrm{Mb}$ from the $C$. muris genome have been made available for download from CryptoDB, of which 7.2 Mb corresponding to coding sequences. Based on these newly added genomic sequences, 7/10 (70\%) of the selected putative species-specific genes appear to have orthologs in C. muris. This information, if known previously, would have decreased dramatically the number of putative species-specific genes predicted by comparative genomics. Despite this limitation, only one C. parvum and one C. hominis gene were shown experimentally by PCR to be putatively specific, the characterisation of these genes is ongoing.

We considered whether the observed ubiquity of the predicted specific genes represented the closeness between $C$. hominis and C. parvum or whether these primers would also amplify orthologous genes from other Cryptosporidium species by testing DNA from $C$. andersoni, C. felis, cervine genotype, C. meleagridis and C. baileyi. Cryptosporidium meleagridis DNA amplified using $80 \%$ of the primers tested, while, C. andersoni,

Table 4 SNP analysis for the ten loci

\begin{tabular}{|c|c|c|c|c|c|c|}
\hline $\begin{array}{l}\text { Gene } \\
\text { name }\end{array}$ & $\begin{array}{l}\text { Gene } \\
\text { annotation }\end{array}$ & $\begin{array}{c}\text { PCR } \\
\text { product } \\
\text { size }\end{array}$ & $\begin{array}{l}\text { Number of } \\
\text { SNPs detected }\end{array}$ & $\begin{array}{c}\text { Average number } \\
\text { of nucleotides } \\
\text { per SNP }\end{array}$ & $\begin{array}{l}\text { Number of Species } \\
\text { specific SNPs (\%) }\end{array}$ & $\begin{array}{c}\text { Number of non } \\
\text { synonymous SNPs } \\
(\%)\end{array}$ \\
\hline Cgd2_80 & $\mathrm{ABC}$ transporter family protein & $266 \mathrm{bp}$ & 7 & 38 & $6(85.5 \%)$ & $1(14.3 \%)$ \\
\hline Cgd2_2430 & $\begin{array}{l}\text { Ximpact ortholog conserved protein } \\
\text { seen in bacteria and eukaryotes }\end{array}$ & $389 \mathrm{bp}$ & 13 & 30 & $9(69.3 \%)$ & $3(23.1 \%)$ \\
\hline Cgd6_200 & Oocyst wall protein 8 & $447 \mathrm{bp}$ & 8 & 56 & $6(75 \%)$ & $2(25 \%)$ \\
\hline Cgd6_5020 & Protein with WD40 repeats & $271 \mathrm{bp}$ & 2 & 136 & $2(100 \%)$ & $1(50 \%)$ \\
\hline Cgd8_2370 & Adenosine kinase like ribokinase & $685 \mathrm{bp}$ & 12 & 58 & $8(66.7 \%)$ & $1(8.4 \%)$ \\
\hline Chro.20156 & Hypothetical protein & $247 \mathrm{bp}$ & 6 & 42 & $5(83.4 \%)$ & $5(83.4 \%)$ \\
\hline Chro.50317 & RNA polymerase $\mathrm{A} /$ beta'$^{\prime} / \mathrm{A}^{\prime \prime}$ subunit & $752 \mathrm{bp}$ & 15 & 51 & $10(66.7 \%)$ & $10(66.7 \%)$ \\
\hline Chro. 50330 & Leucyl tRNA synthetase & $368 \mathrm{bp}$ & 3 & 123 & $3(100 \%)$ & $0(0 \%)$ \\
\hline Chro.30149 & Ubiquitin-protein ligase 1 & $331 \mathrm{bp}$ & 0 & 331 & & \\
\hline Chro.50457 & $\begin{array}{l}\text { Erythrocyte membrane-associated } \\
\text { antigen }\end{array}$ & 394 bp & 12 & 33 & 12 (100\%) & $5(41.7 \%)$ \\
\hline
\end{tabular}

This table details the number of SNPs detected by PCR products sequence analysis of ten novel genetic loci. For each gene, the number and proportion of species-specific SNPs were provided. The effect of the genetic polymorphism on amino acid composition was also indicated. 
Table 5 Genetic differences between Cryptosporidium isolates tested

\begin{tabular}{|c|c|c|c|c|c|}
\hline & C. hominis & C. parvum & Anthroponotic C. parvum & C. cuniculus & C. meleagridis \\
\hline C. hominis & 0 & & & & \\
\hline C. parvum & $77(1.72 \%)$ & 0 & & & \\
\hline Anthroponotic C. parvum & $78(1.75 \%)$ & $5(0.12 \%)$ & 0 & & \\
\hline C. cuniculus & $12(0.27 \%)$ & $75(1.68 \%)$ & $76(1.70 \%)$ & 0 & \\
\hline C. meleagridis & $157(5.50 \%)$ & $144(5.05 \%)$ & $144(5.05 \%)$ & 155 (5.50\%) & 0 \\
\hline
\end{tabular}

Based on PCR product sequence analysis, the genetic differences (number and percentage of base pair polymorphisms) between the main strain groups was determined.

cervine genotype and $C$. felis DNA amplified with only $10 \%$ of primers. This result is in accordance with the taxonomy and evolution of Cryptosporidium species [20]. In fact, amongst the species tested, C. meleagridis is the closest species to the cluster formed by $C$. hominis, C. parvum and C. cuniculus based on partial SSU rRNA gene [20]. Cryptosporidium meleagridis DNA did not amplify with primers of Cgd2_2430 and Chro.20156. This could be explained by either nucleotide mismatch in the primer region or that the genes were missing.

PCR screening and sequencing of genes found experimentally to be common to both species provided de novo sequence information at incomplete regions of the Cryptosporidium genomes and was used to examine polymorphism in these regions. PCR product sequence analysis revealed interesting genetic variation as SNPs. In this study, 78 SNPs were detected, $78.3 \%$ (61) of which were species-specific. The presence of speciesspecific SNPs was reported previously from several genetic markers and has been exploited for Cryptosporidium genotyping and subtyping [21]. PCR-RFLP of the SSU rRNA [22], COWP [23], dihydrofolate reductase (DHFR) gene [24], thrombospondin related adhesive protein of Cryptosporidium-1 (TRAP-C1) [25] and TRAP-C2 [26], polythreonine (Poly-T) repeats [27] and heat shock protein 70 (HSP70) [28] genes allow discrimination between Cryptosporidium species from various sources. In a similar manner, the newly identified SNPs could be also used for Cryptosporidium genotyping, especially by PCR-RFLP and/or sequencing. The majority of the SNPs detected (64.2\%) were synonymous. It has long been assumed that synonymous SNPs are inconsequential as the primary sequence of the protein is preserved. However, it has been demonstrated that synonymous mutations can alter the structure, function and expression level of the protein by affecting messenger RNA splicing, stability, protein folding and structure [29]. In addition, Ge and colleagues [30] used a genome wide analysis and described a high number of nucleotide substitution patterns in C. parvum and C. hominis orthologous protein coding genes. The authors also reported a high number of non-synonymous SNPs in genes involved in hostparasite interactions, mainly genes with transmembrane domains or signal peptides [30].
The sequence analysis of $C$. meleagridis PCR products allowed data enrichment as this species is distant from $C$. hominis and $C$. parvum. In fact, among the genes assessed here, $C$. meleagridis species had 108 additional SNPs, 20 of which are in the Chro.30149 gene. For Chro.30149 gene, C. meleagridis has in average 1 SNP every 15 nucleotide. Surprisingly, all $C$. meleagridis SNPs are synonymous. Interestingly, no SNP was detected in this gene from $C$. hominis and C. parvum DNA. Chro.30149 has a predicted function as Ubiquitin ligase. This gene is a housekeeping gene and shows a low level of sequence divergence between species and isolates when compared to contingency genes consistently under environmental pressure and characterized by higher spontaneous mutation rates [31].

The newly identified SNPs were used to determine genetic differences between the main Cryptosporidium species and subtypes tested. This analysis showed that the genetic difference between $C$. hominis and $C$. parvum was only $1.72 \%$. Within $C$. parvum group, the anthroponotic subtype isolates showed only $0.12 \%$ from the main zoonotic $C$. parvum isolates. The $C$. cuniculus isolates exhibited $0.27 \%$ genetic differences to $C$. hominis isolates. In addition, extremely low sequence variability between $C$. hominis and $C$. cuniculus was observed using the common genotyping loci [13]. Based on these data and supported by morphological analysis and experimental infection, rabbit genotype was considered synonymous with $C$. cuniculus [13].

In addition, sequence analysis allowed us to perform a robust and novel MLA. The Neighbour-Joining phylogenetic tree clearly grouped and discriminated with high bootstrap values the previously described lineages of Cryptosporidium subtypes. Therefore, these genetic loci represent potential powerful targets for Cryptosporidium genotyping and subtyping purposes. Especially since these genes are stable and slow mutating, unlike the currently used Cryptosporidium typing targets (gp60, mini- and microsatellites).

Mini and Microsatellites are repetitive versatile DNA repeats known to influence the structure and expression of protein-coding genes and to be responsive to environmental signals [32,33]. The microsatellites abundance and high variability made them the genetic markers of choice for several applications (individual identity, 


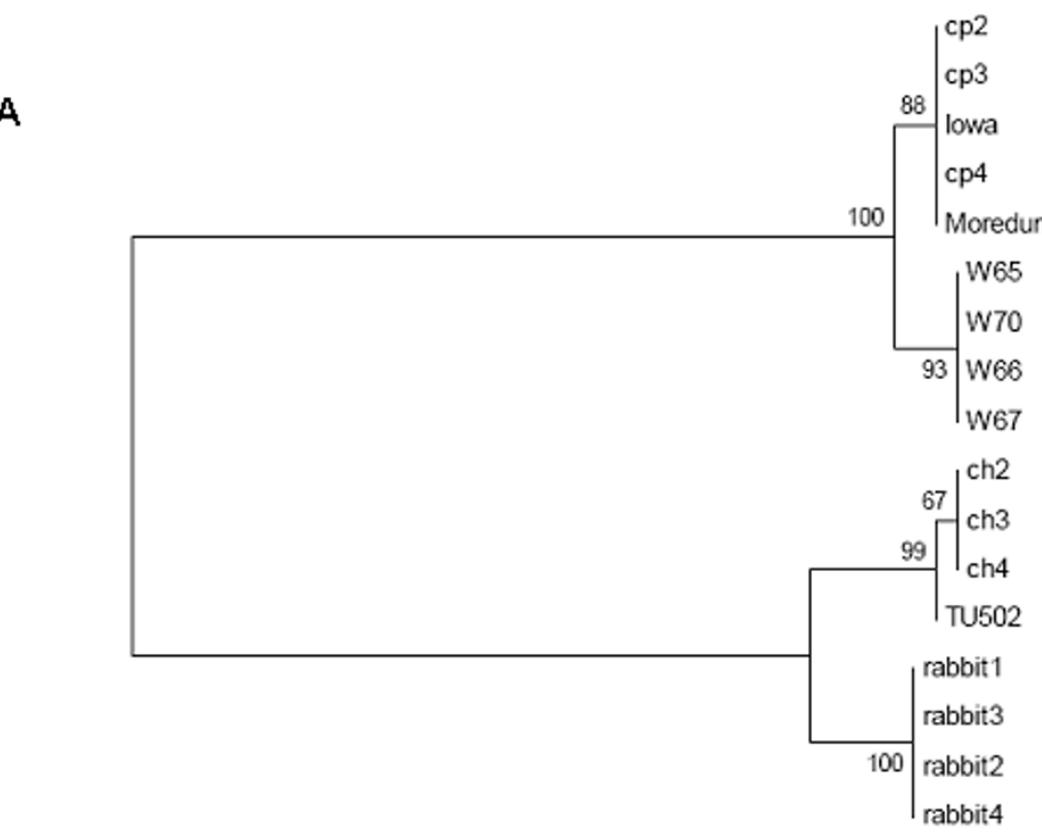

B

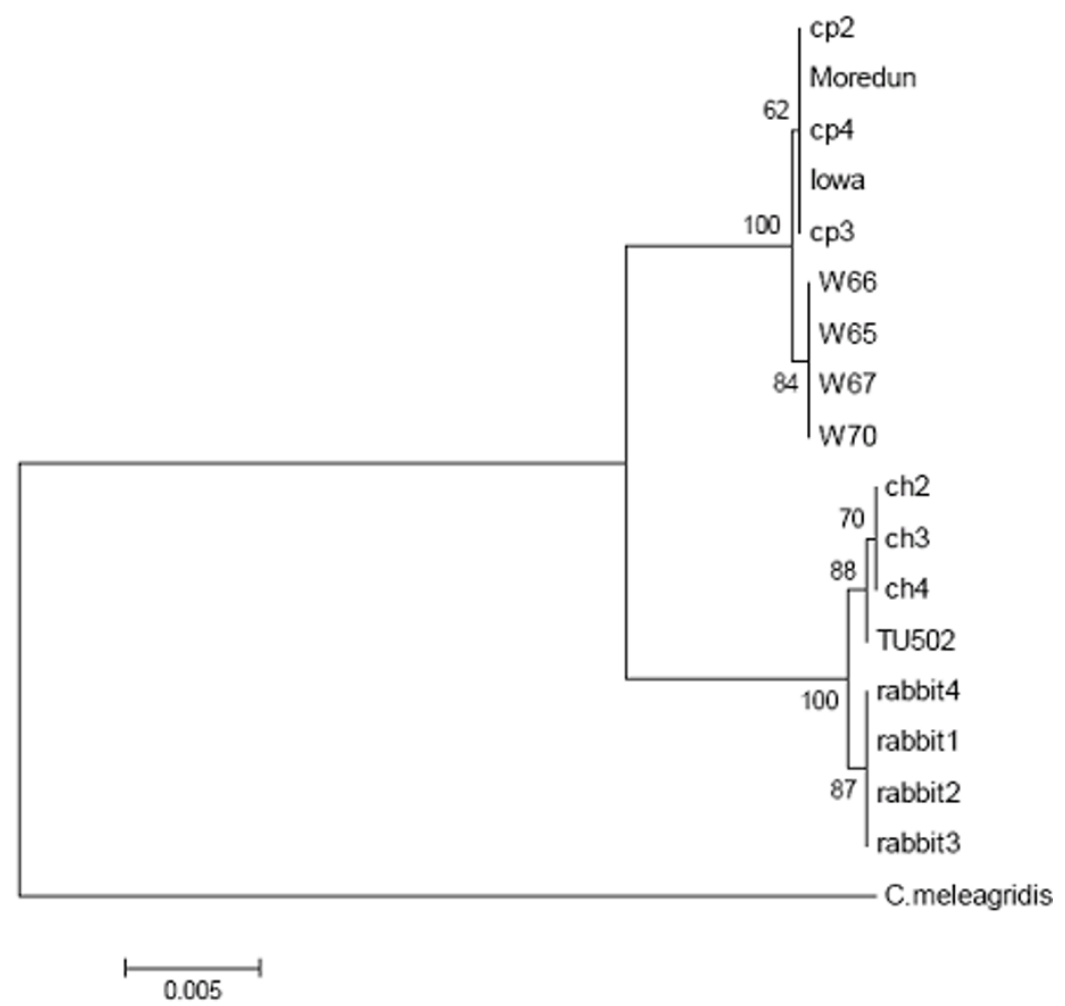

Figure 2 Phylogenetic Tree based on the gene sequences of $\mathbf{1 0}$ new loci and the COWP gene sequence. The trees were constructed using Neighbour-Joining algorithm of MEGA software. A: Phylogenetic tree constructed using C. parvum, C. hominis and C. cuniculus sequences. B: Phylogenetic tree with C. meleagridis as an out-group. 
forensics, parentage, genetic structure, epidemiology and phylogenetics [34]. However, because of the instability of microsatellite markers, extra care should be taken when interpreting microsatellite-based typing data [35]. Similarly, gp60 is hypervariable and under selective pressure as it mediates parasite attachment to host cells [36]. In fact, discrepancies and limitations of these markers for Cryptosporidium typing have been reported. Hunter and colleagues [37] described the difficulty in interpreting the presence of different subtypes in outbreak setting and Widmer [38] reported that gp60 might not be a reliable marker of C. parvum and C. hominis population structure. The ten novel loci, described in this study, showed excellent discriminatory power and consistency to assess phylogenetic relationships at the species and infra-species levels. These findings suggest that these loci could be alternative valuable genotyping and subtyping targets for Cryptosporidium. However, their stability should be assessed in an extensive collection of isolates from different subtype families and geographical locations to validate their discriminatory power.

\section{Conclusions}

In this study, comparative genomics were used to identify putative C. parvum and C. hominis species-specific genes. Despite the fact that the majority of the predicted genes were common to both species and some to $C$. meleagridis, experimental evidence was found for one specific gene for each species. The ten novel genetic loci studied showed an interesting polymorphism. In fact, sequence analysis of PCR products revealed multiple SNPs, the majority of which were species-specific. These SNPs were stable and consistent across Cryptosporidium species and subtypes. These results showed that the ten novel genetic loci can potentially be used to assess the phylogenetic distance and relationships at the species and infra-species level of human infective Cryptosporidium isolates. In addition, the paired SNP analysis was found to be a good strategy to assess the genetic divergence of the isolates tested.

\section{Methods}

Reciprocal Blast was used to identify genes with high sequence variability between $C$. parvum and C. hominis. This is a variant of Blast (Basic local alignment search tool), originally described by Altschul and colleagues [39] and is a common computational tool for predicting putative orthologs http://www.ncbi.nlm.nih.gov/blast/ blast_overview.shtml. Subsequently, each of the $\sim 3900$ genes of C. parvum and C. hominis was assigned a similarity score. Only sequences which returned genes with less than $10 \%$ sequence similarity from the other genome were considered. These coding sequences are putatively species-specific genes. A secondary screen was performed as follows: each gene was individually tested using Blastn algorithm http://blast.ncbi.nlm.nih. gov/Blast.cgi to confirm specificity and reveal any sequence similarity to genes from other Cryptosporidium species. Furthermore, orthology queries were performed using CryptoDB database. Whenever a gene showed sequence similarity, it was eliminated from the selection. This secondary screen increased the prediction stringency.

Amongst the putative species-specific genes, initially 10 genes were selected with preference to annotated genes and tested experimentally by PCR. For each gene, a pair of primers was designed using OligoPerfect ${ }^{\mathrm{mi}}$ Designer software http://www.invitrogen.com and supplied by Operon/ Eurofins MWG (Cologne, Germany). Table 1 details the genes selected, the primer sequences and the PCR product sizes for each gene tested. In addition, reference primers Cry15 and Cry9 amplifying a 555 bp of the COWP gene [23] were used as a positive control. PCR conditions were carried out as described previously [40]. PCR screening of putative species genes was performed by testing a panel of DNA clinical samples isolated as described previously [41] and archived in the national collection at the UK Cryptosporidium Reference Unit (CRU) [42]. Each isolate was characterised initially by PCR-RFLP of the Cryptosporidium oocyst wall protein (COWP) gene [23] and by realtime PCR using simplex Lib 13 primers for C. parvum and C. hominis [43] prior to sequencing part of the SSU rRNA and gp60 genes $[44,45]$. A total number of 14 Cryptosporidium clinical isolates was tested (Table 2). This includes DNA from three C. hominis isolates (Ch2, $\mathrm{Ch} 3$ and $\mathrm{Ch} 4)$, 3 C. parvum isolates $(\mathrm{Cp} 2, \mathrm{Cp} 3$, and $\mathrm{Cp} 4)$ and 4 C. parvum anthroponotic subtype isolates (W7265, W7266, W7267 and W7270). The anthroponotic C. parvum group isolates were previously identified as gp60 subtype family IIc (CRU unpublished data). This subtype family was reported to infect only humans, and was never reported in an animal species [1]. The anthroponotic nature of the IIc subtype family was supported by extensive subtyping investigations of human and bovine cryptosporidiosis in Portugal, USA, Canada, UK, Ireland, Slovenia, the Netherlands and Australia [1,46-48]. In addition, the DNA of one rabbit genotype (C. cuniculus) isolate from the Northamptonshire outbreak [12] and three sporadic cases (Chalmers et al., manuscript in preparation) were also analysed. These DNA samples originated from patients with cryptosporidial diarrhoea from different geographical locations in UK and were chosen as a representative collection of the different strains circulating in the country. Furthermore, the genomic DNA of 3 reference strains C. parvum Iowa (ATCC/LGC Promochem, Teddington, UK), C. parvum Moredun (Moredun Research Institute, Midlothian, UK) and C. hominis TU502 (BEI Resources, Manassas, 
USA) were tested. Table 5 details the origin and the genotyping data of the tested isolates. In addition, we considered whether the designed primers would amplify orthologous genes from other Cryptosporidium species, therefore, DNA from other Cryptosporidium species and genotypes was kindly donated by CRU and tested; this includes C. andersoni (W13086), C. felis (W14508), cervine genotype (W15916), C. meleagridis (W10509) and C. baileyi (W14184).

Positive PCR products were purified using QIAquick ${ }^{\circ}$ PCR purification Kit (Qiagen Ltd., Crawley, UK). Purified PCR products were sequenced in both directions using PCR primers. We used 2 independent sequencing facilities: the genome lab, John Innes Centre http:// www.jicgenomelab.co.uk and the sequencing service at the University of Dundee http://www.dnaseq.co.uk, both using Dye-terminator chemistry technology and Applied Biosystems automated capillary DNA sequencer (3770 and 3730 model, respectively). Sequences were assembled using CAP3 software http://pbil.univ-lyon1.fr/ cap3.php[49] and aligned using Align $\mathrm{X}^{\bullet}$ application of Vector NTI Advance ${ }^{\mathrm{mm}} 10$ software http://www.Invitrogen.com. Phylogenetic analysis was performed using MEGA (Molecular Evolutionary Genetic Analysis) software http://www.megasoftware.net[50].

\section{Additional material}

\section{Additional file 1: Alignment of PCR product sequences of} Cryptosporidium clinical isolates and reference strains. This file shows the PCR product sequences for the ten novel genetic loci and the COWP gene. The sequences are available online (see result section). The alignment shows the position of each SNP detected. The totality of the SNPs was used for MLA and calculation of genetic differences between Cryptosporidium species and isotypes tested.

\begin{abstract}
Acknowledgements
The authors thank Dr Stephen Hadfield and Dr Guy Robinson, CRU for scientific support. Thanks are also extended to Dr Brent Emmerson, School of Biological sciences, University of East Anglia for scientific discussions. Financial support

This work was partially supported by funds from the European Commission for the HEALTHY WATER project (FOOD-CT-2006-036306). The authors are solely responsible for the content of this publication. It does not represent the opinion of the European Commission. The European Commission is not responsible for any use that might be made of data appearing therein.
\end{abstract}

\section{Author details}

${ }^{1}$ Biomedical Research Centre, School of Medicine, Health Policy and Practice, University of East Anglia, Norwich NR4 7TJ, UK. ${ }^{2}$ CNRS UMR 6543. Institute of Signalling, Developmental Biology and Cancer Centre de Biochimie, Faculté des Sciences, 06108 Nice cedex 2, France. ${ }^{3}$ UK Cryptosporidium Reference Unit, Public Health Wales, Microbiology ABM, Singleton Hospital, Swansea SA2 8QA, UK.

\section{Authors' contributions}

MB carried out the experimental testing of the predicted putative speciesspecific genes, sequence alignment and data analysis and drafted the manuscript. KMT conceived the study, provided technical guidance, coordinated the study and helped to draft the manuscript. RC performed the comparative genomic analysis. RMC participated in the design of the study and helped to draft the manuscript. KE carried out DNA extraction from clinical samples and genotyping and subtyping of the isolates at CRU and helped to draft the manuscript. PRH coordinated the study and carried out data analysis and MLA. All authors read and approved the final manuscript.

Received: 12 May 2010 Accepted: 9 August 2010

Published: 9 August 2010

\section{References}

1. Xiao L, Fayer R: Molecular characterisation of species and genotypes of Cryptosporidium and Giardia and assessment of zoonotic transmission. Int J Parasitol 2008, 38:1239-1255.

2. Cacciò S, Pozio E: Advances in the epidemiology, diagnosis and treatment of cryptosporidiosis. Expert Rev Anti Infect Ther 2006, 4:429-443.

3. Cacciò S: Molecular epidemiology of human cryptosporidiosis. Parassitologia 2005, 47:185-192.

4. Xiao L, Ryan UM: Cryptosporidiosis: an update in molecular epidemiology. Curr Opin Infect Dis 2004, 17:483-490.

5. Morgan UM, Deplazes P, Forbes DA, Spano F, Hertzberg H, Sargent KD, Elliot A, Thompson RC: Sequence and PCR-RFLP analysis of the internal transcribed spacers of the rDNA repeat unit in isolates of Cryptosporidium from different hosts. Parasitology 1999, 118(Pt 1):49-58.

6. Robertson L, Gjerde BK: Cryptosporidium oocysts: challenging adversaries? Trends Parasitol 2007, 23:344-347.

7. Hunter PR, Thompson RC: The zoonotic transmission of Giardia and Cryptosporidium. Int J Parasitol 2005, 35:1181-1190.

8. Xiao L, Feng Y: Zoonotic cryptosporidiosis. FEMS Immunol Med Microbiol 2008, 52:309-323.

9. Hunter P, Hughes S, Woodhouse S, Raj N, Syed Q, Chalmers RM, Verlander NQ, Goodacre J: Health sequelae of human cryptosporidiosis in immunocompetent patients. Clin Infect Dis 2004, 39:504-510.

10. Cama VA, Bern C, Roberts J, Cabrera L, Sterling CR, Ortega Y, Gilman RH, Xiao L: Cryptosporidium species and subtypes and clinical manifestations in children, Peru. Emerg Infect Dis 2008, 14:1567-1574.

11. Robinson G, Chalmers RM: The European Rabbit (Oryctolagus cuniculus), a Source of Zoonotic Cryptosporidiosis. Zoonoses Public Health 2009.

12. Chalmers R, Robinson G, Elwin K, Hadfield SJ, Xiao L, Ryan U, Modha D, Mallaghan C: Cryptosporidium sp. rabbit genotype, a newly identified human pathogen. Emerg Infect Dis 2009, 15:829-830.

13. Robinson G, Wright S, Elwin K, Hadfield SJ, Katzer F, Bartley PM, Hunter PR, Nath M, Innes EA, Chalmers RM: Re-description of Cryptosporidium cuniculus Inman and Takeuchi, 1979 (Apicomplexa: Cryptosporidiidae): Morphology, biology and phylogeny. Int J Parasitol 2010.

14. Abrahamsen M, Templeton TJ, Enomoto S, Abrahante JE, Zhu G, Lancto CA, Deng M, Liu C, Widmer G, Tzipori S, Buck GA, Xu P, Bankier AT, Dear PH, Konfortov BA, Spriggs HF, lyer L, Anantharaman V, Aravind L, Kapur V: Complete genome sequence of the apicomplexan, Cryptosporidium parvum. Science 2004, 304:441-445.

15. Xu P, Widmer G, Wang Y, Ozaki LS, Alves JM, Serrano MG, Puiu D, Manque P, Akiyoshi D, Mackey AJ, Pearson WR, Dear PH, Bankier AT, Peterson DL, Abrahamsen MS, Kapur V, Tzipori S, Buck GA: The genome of Cryptosporidium hominis. Nature 2004, 431:1107-1112.

16. Widmer G, Carlton JM, Silva JC, London E: The Cryptosporidium muris genome project: a progress report. II International Giardia and Cryptosporidium Conference Centro Cultural Universitario, Morelia, Michoacan, Mexico 2007, 64.

17. Widmer G, Lin L, Kapur V, Feng X, Abrahamsen MS: Genomics and genetics of Cryptosporidium parvum: the key to understanding cryptosporidiosis. Microbes Infect 2002, 4:1081-1090.

18. Pain A, Crossman L, Parkhill J: Comparative Apicomplexan genomics. Nat Rev Microbiol 2005, 3:454-455.

19. Kuo C-H, Kissinger JC: Consistent and contrasting properties of lineagespecific genes in the apicomplexan parasites Plasmodium and Theileria. BMC Evol Biol 2008, 8:108.

20. Xiao L, Fayer R, Ryan U, Upton SJ: Cryptosporidium taxonomy: recent advances and implications for public health. Clin Microbiol Rev 2004 17:72-97. 
21. Sulaiman I, Xiao L, Lal AA: Evaluation of Cryptosporidium parvum genotyping techniques. App/ Environ Microbiol 1999, 65:4431-4435.

22. Xiao L, Escalante L, Yang C, Sulaiman I, Escalante AA, Montali RJ, Fayer R, Lal AA: Phylogenetic analysis of Cryptosporidium parasites based on the small-subunit rRNA gene locus. Appl Environ Microbiol 1999, 65:1578-1583.

23. Spano F, Putignani L, MCLauchlin J, Casemore DP, Crisanti A: PCR-RFLP analysis of the Cryptosporidium oocyst wall protein (COWP) gene discriminates between C. wrairi and C. parvum, and between C. parvum isolates of human and animal origin. FEMS Microbiol Lett 1997, 150:209-217.

24. Gibbons CL, Gazzard BG, Ibrahim M, Morris-Jones S, Ong CSL, Awad-ElKariem FM: Correlation between markers of strain variation in Cryptosporidium parvum: evidence of clonality. Parasitol Int 1998, 47:139-147.

25. Spano F, Putignani L, Guida S, Crisanti A: Cryptosporidium parvum: PCRRFLP analysis of the TRAP-C1 (thrombospondin-related adhesive protein of Cryptosporidium-1) gene discriminates between two alleles differentially associated with parasite isolates of animal and human origin. Exp Parasitol 1998, 90:195-198.

26. Sulaiman I, Xiao L, Yang C, Escalante L, Moore A, Beard CB, Arrowood MJ, Lal AA: Differentiating human from animal isolates of Cryptosporidium parvum. Emerg Infect Dis 1998, 4:681-685.

27. Carraway M, Tzipori S, Widmer G: A new restriction fragment length polymorphism from Cryptosporidium parvum identifies genetically heterogeneous parasite populations and genotypic changes following transmission from bovine to human hosts. Infect Immun 1997 65:3958-3960

28. Gobet $P$, Toze S: Sensitive genotyping of Cryptosporidium parvum by PCR-RFLP analysis of the 70-kilodalton heat shock protein (HSP70) gene. FEMS Microbiol Lett 2001, 200:37-41.

29. Hunt R, Sauna ZE, Ambudkar SV, Gottesman MM, Kimchi-Sarfaty C: Silent (synonymous) SNPs: should we care about them? Methods Mol Biol 2009, 578:23-39.

30. Ge G, Cowen L, Feng X, Widmer G: Protein Coding Gene Nucleotide Substitution Pattern in the Apicomplexan Protozoa Cryptosporidium parvum and Cryptosporidium hominis. Comp Funct Genomics 2008, 879023.

31. Barry JD, Ginger $M L$, Burton $P$, McCulloch R: Why are parasite contingency genes often associated with telomeres? Int J Parasitol 2003, 33:29-45.

32. Schmidt AL, Anderson LM: Repetitive DNA elements as mediators of genomic change in response to environmental cues. Biol Rev Camb Philos Soc 2006, 81:531-543.

33. Richard GF, Kerrest A, Dujon B: Comparative genomics and molecular dynamics of DNA repeats in eukaryotes. Microbiol Mol Biol Rev 2008, 72:686-727.

34. Buschiazzo E, Gemmell NJ: The rise, fall and renaissance of microsatellites in eukaryotic genomes. Bioessays 2006, 28:1040-1050.

35. Klaassen CH: MLST versus microsatellites for typing Aspergillus fumigatus isolates. Med Mycol 2009, 47(Suppl 1):S27-33.

36. Okhuysen PC, Chappell CL: Cryptosporidium virulence determinants-are we there yet? Int J Parasitol 2002, 32:517-525.

37. Hunter PR, Wilkinson DC, Lake IR, Harrison FC, Syed Q, Hadfield SJ, Chalmers RM: Microsatellite typing of Cryptosporidium parvum in isolates from a waterborne outbreak. J Clin Microbiol 2008, 46:3866-3867.

38. Widmer G: Meta-analysis of a polymorphic surface glycoprotein of the parasitic protozoa Cryptosporidium parvum and Cryptosporidium hominis. Epidemiol Infect 2009, 137:1800-1808.

39. Altschul S, Gish W, Miller W, Myers EW, Lipman DJ: Basic local alignment search tool. J Mol Biol 1990, 215:403-410.

40. Bouzid M, Heavens D, Elwin K, Chalmers RM, Hadfield SJ, Hunter PR, Tyler KM: Whole genome amplification (WGA) for archiving and genotyping of clinical isolates of Cryptosporidium species. Parasitology 2010, 137:27-36.

41. Elwin K, Chalmers RM, Roberts R, Guy EC, Casemore DP: Modification of a rapid method for the identification of gene-specific polymorphisms in Cryptosporidium parvum and its application to clinical and epidemiological investigations. Appl Environ Microbiol 2001, 67:5581-5584.

42. Chalmers RM, Elwin K, Thomas AL, Guy EC, Mason B: Long-term Cryptosporidium typing reveals the aetiology and species-specific epidemiology of human cryptosporidiosis in England and Wales, 2000 to 2003. Euro Surveill 2009, 14.
43. Tanriverdi S, Arslan MO, Akiyoshi DE, Tzipori S, Widmer G: Identification of genotypically mixed Cryptosporidium parvum populations in humans and calves. Mol Biochem Parasitol 2003, 130:13-22.

44. Xiao L, Singh A, Limor J, Graczyk TK, Gradus S, Lal A: Molecular characterization of Cryptosporidium oocysts in samples of raw surface water and wastewater. Appl Environ Microbiol 2001, 67:1097-1101.

45. Mallon M, MacLeod A, Wastling J, Smith H, Reilly B, Tait A: Population structures and the role of genetic exchange in the zoonotic pathogen Cryptosporidium parvum. J Mol Evol 2003, 56:407-417.

46. Alves M, Xiao L, Antunes F, Matos O: Distribution of Cryptosporidium subtypes in humans and domestic and wild ruminants in Portugal. Parasitol Res 2006, 99:287-292.

47. Xiao L: Molecular epidemiology of cryptosporidiosis: an update. Exp Parasitol 2010, 124:80-89.

48. Soba B, Logar J: Genetic classification of Cryptosporidium isolates from humans and calves in Slovenia. Parasitology 2008, 135:1263-1270.

49. Huang X, Madan A: CAP3: A DNA sequence assembly program. Genome Res 1999, 9:868-877.

50. Tamura K, Dudley J, Nei M, Kumar S: MEGA4: Molecular Evolutionary Genetics Analysis (MEGA) software version 4.0. Mol Biol Evol 2007. 24:1596-1599.

doi:10.1186/1471-2180-10-213

Cite this article as: Bouzid et al:: Multi-locus analysis of human infective Cryptosporidium species and subtypes using ten novel genetic loci. BMC Microbiology 2010 10:213.

\section{Submit your next manuscript to BioMed Central and take full advantage of:}

- Convenient online submission

- Thorough peer review

- No space constraints or color figure charges

- Immediate publication on acceptance

- Inclusion in PubMed, CAS, Scopus and Google Scholar

- Research which is freely available for redistribution

Submit your manuscript at www.biomedcentral.com/submit
C) Biomed Central 